\title{
INDO ALÉM DA TEMÁTICA HISTÓRICA: a linguagem pictórica como recurso pedagógico.
}

\author{
Mônia L. Silvestrin \\ Ana Gilka D. Carneiro ${ }^{1}$
}

Resumo: O presente artigo discute algumas possibilidades de utilização das artes plásticas, mais especificamente a pintura como recurso didático para o ensino da história. Enfatizando questões metodológicas, procuramos apresentar alternativas ao já conhecido trabalho com quadros de temática histórica, privilegiando o diálogo com a história e teorias da arte.

Palavras-chave: História - Educação - Artes - Pintura

Trabalhar com artes plásticas no ensino da história é uma verdadeira aventura. Em primeiro lugar, aponta-se o prazer de poder fazer uso de uma linguagem artística na busca por outras possibilidades de construção do conhecimento histórico em sala de aula, estimulando a criatividade de alunos e professores, contribuindo para a construção de novos olhares. Por outro lado, depara-se com a dificuldade em encontrar a bibliografia necessária, o que complica bastante a nossa missão: não existe material específico sobre o assunto, encontrando-se no máximo, artigos que tratam somente do conteúdo transmitido nos quadros de temática histórica, abordagem esta que contempla apenas uma das perspectivas possíveis de serem exploradas a partir de representações visuais. Buscando referências em livros de história da arte e em algum material a respeito de metodologia de ensino que aborde outras linguagens artísticas já trabalhadas como recurso didático - o cinema por exemplo - encontramos inspiração de como proceder no caso da pintura ${ }^{2}$, nos propondo

\footnotetext{
1 Alunas do curso de graduação em História da Universidade Federal do Paraná.

${ }^{2}$ Neste texto optamos por um recorte mais preciso, privilegiando dentre as chamadas Artes Visuais, a pintura nas suas mais variadas técnicas, suportes e estilos. Nada impede, entretanto, que as sugestões aqui apontadas forneçam subsídios para outras abordagens e objetos.
} 
a pensar possibilidades de abordagens histórico-metodológicas diferenciadas do objeto artístico, oferecendo outras alternativas às visões tradicionais, já exploradas. Tendo como partida esse sobrevôo multidisciplinar, nos propomos a destacar alguns pontos e levantar problemáticas que julgamos importantes, procurando discuti-las de maneira breve neste pequeno texto, tendo consciência de que todas as questões estão praticamente em aberto, são apenas apontamentos para uma possível reflexão.

Como trabalhar com o universo da arte do ponto de vista histórico-pedagógico? O que entendemos por arte? Pintura? De onde partir? Embora os conceitos e modelos teóricos da historiografia da arte sejam abundantes e ainda que demandem escolhas em boa medida subjetivas por parte do professor, podemos destacar algumas questões essenciais à nossa proposta pedagógica. Primeiro, a necessidade de considerarmos as obras de arte como representações, construídas pelo artista jamais a verdade do que aconteceu - e que, de uma maneira ou outra, estão inscritas em um determinado espaço e temporalidade. Embora possam, sob a forma de documento, ser utilizadas também para "provar" um determinado passado, acreditamos que tomar as pinturas como produto de uma certa visão de mundo ou leitura da "realidade", parece fornecer perspectivas mais ricas de abordagem, principalmente porque coloca em pauta a questão da linguagem e sua historicidade. A pintura como obra de arte tem uma linguagem pictórica que lhe é peculiar e que precisa ser apreendida por quem pretende entendê-la - mesmo como um simples admirador - tornando-se imprescindível que o professor interessado em utilizá-la como recurso didático domine o saber específico que a fundamenta. Ou seja, é necessário educar o olhar para a arte, instrumentalizá-lo e isso significa, além de conhecer um pouco que seja de História da Arte e metodologias de pesquisa, ter acesso a alguma teoria referente aos elementos e técnicas característicos das representações visuais - eis mais um pressuposto essencial.

Em um segundo momento, a obra de arte como fruto do seu tempo nos coloca outra questão: o problema de pensarmos 
a relação entre arte e sociedade. Fugindo de esquemas redutores e simplistas, pensamos que o objeto artístico não pode nem deve ser entendido, por um lado, como mero reflexo da realidade, das estruturas econômicas ou determinado por meios de produção e circulação de mercadorias e, por outro, como isolado em si mesmo, destacado do momento histórico em que foi criado, das condições especificas que possibilitaram seu aparecimento. Acreditamos sim, na possibilidade de pensarmos essa questão - sempre polêmica - do ponto de vista de uma teoria relacional, entendendo a arte como fruto das possibilidades e determinações dadas tanto pelo artista enquanto indivíduo criador, como pelas configurações sociais da sua própria época. Ambas as instâncias - indivíduo e sociedade - são tomadas enquanto faces diferentes de um mesmo processo, indissociáveis e em contínuo movimento. É o que coloca Norbert ELIAS (1995, p. 89), no seu livro sobre Mozart, quando afirma que "a autonomia relativa da obra de arte e o complexo de problemas à ela associados não nos eximem da obrigação de investigar a conexão entre a experiência e o destino do artista criador em sua sociedade, ou seja, entre esta sociedade e as obras produzidas pelo artista" convidando-nos a assumir as responsabilidades de um pensamento complexo, instigante na sua capacidade de fugir a dualidades e posições cômodas, inovador nas suas inquietações.

\section{Nos meandros da arte}

"Dizer o que seja arte é coisa difícil. Um sem número de tratados de estética debruçou-se sobre o problema, procurando situá-lo, procurando definir o conceito. Mas, se buscamos uma resposta clara e definitiva, decepcionamo-nos: elas são divergentes, contraditórias, além de freqüentemente se pretenderem exclusivas (...) Para decidir o que é ou não arte, nossa cultura possui instrumentos específicos. Um deles, essencial, é o discurso sobre o objeto artístico, em que reconhecemos competência e autoridade. Esse discurso é o que profere o crítico, o historiador da arte, o perito, o 
conservador de museu. São eles que conferem o estatuto de arte a um objeto".

Jorge COLI (1983, pp. 11-13), historiador da arte, além de nos chamar a atenção para a dificuldade em definir parâmetros que possam nos dizer o que é arte, nos lembra que a delimitação de tal conceito é uma construção discursiva, elaborada por especialistas e instituições, portanto mutável, fruto de um tempo e cultura específicos. Cada época escolhe suas obras e seus gênios... Mesmo as unanimidades, referendadas pela tradição, são apropriadas por motivos diferentes a cada momento histórico - nada garante que um juízo de valor, que uma qualificação seja eterna. Tendo consciência dessa transitoriedade e das tantas concepções de arte existentes, destacamos duas que fornecem melhores subsídios para orientar um primeiro diálogo entre arte e história: os estudos formalistas, iniciados por Wölfflin na virada do século, e a proposta dos estudos iconológicos, que tem seu maior representante na figura de Panofsky ${ }^{3}$.

Ao proporem seus modelos explicativos para o fenômeno artístico, tais teorias ajudaram a constituir, a partir do final do século XIX, uma tradição historiográfica da arte marcada pela busca incessante de metodologias rigorosas, desejo consonantes com os ideais oitocentistas de ciência. A teoria formalista debruçase, como o próprio nome diz, sobre os aspectos formais da obra de arte e tem na idéia de estilo - que se baseia na recorrência de determinadas características comuns às obras de um artista ou de uma época - seu conceito fundamental. Ou seja, buscando elementos formais, dispostos sob a forma de oposição - linear versus pictural; planos versus profundidade; luz versus sombra... - procura-se identificar um modelo específico no modo como o autor realiza a composição do quadro, como ele dispõe e harmoniza os diversos elementos que Ihes são pertinentes, situando suas opções no seu tempo, espaço e cultura. $O$ significado ou tema da obra, que para os autores formalistas fica

\footnotetext{
${ }^{3}$ São olhares de pontos de vista diversos e que privilegiam aspectos diferentes da obra de arte, aqui abordados de forma superficial, apenas como indicativo, ficando aberto ao professor interessado, a possibilidade de buscar o aprofundamento - inclusive lendo outros autores e escolas.
} 
sempre em segundo plano, é o que fundamenta a nossa segunda opção teórica: a interpretação iconológica encontra na análise da imagem, na compreensão do sentido dado a ela pelas mais diversas e possíveis interpretações, a sua especificidade. Partindo da idéia de um possível "inconsciente" coletivo de imagens e representações, esses estudiosos vão procurar elucidar as transformações pelas quais passam essas imagens e ícones, utilizando-se tanto da diacronia como da sincronia para perceber os sentidos dados ao simbólico e as apropriações feitas pelas diferentes culturas, em recortes temporais e espaciais os mais diversos. Embora a tentação por transformar categorias específicas em modelos universais, atemporais e abstratos seja grande e normalmente aconteça, é o caráter eminentemente histórico - ao menos originalmente - das teorias explicitadas acima que nos permite utilizá-las no ensino da história e propormos um trabalho pedagógico a partir e toda e qualquer pintura, independente do seu tema ser histórico ou não.

\section{Possibilidades de abordagens metodológicas}

Tendo em vista as questões discutidas até agora e inspirados nas teorias formalista e iconológica, propomos inicialmente quatro alternativas possíveis para o trabalho em sala de aula.

1. A historicidade da linguagem - a partir de quadros de temporalidades diferentes, procurar relacionar as mudanças ocorridas na maneira como eles são compostos, pintados, criados - ou seja, na sua linguagem, no estilo ou movimento artístico - com mudanças e acontecimentos referentes a historicidades, culturas e espaços específicos. Comparando uma pintura da Alta Idade Média e uma outra do início do Renascimento podemos perceber mudanças de pensamento, imaginário e visão de mundo ocorridas nesse período, de alguma forma reveladas nas obras de seus artistas, relacionando-as com as possíveis configurações sociais, econômicas e políticas próprias desses períodos. Por exemplo, a passagem do 
teocentrismo para o antropocentrismo na Europa do século XV, evidenciada na pintura pelo abandono da imobilidade e do extremo simbolismo das representações medievais em função da busca pelo real, pela representação exata do mundo conhecido, tendo o homem como medida de todas as coisas evidenciando elementos fundamentais do pensamento humanista. Ou ainda, a crescente ascensão de possíveis valores burgueses evidenciados através dos novos sentidos simbólicos dados às imagens, da ênfase dada às representações do cotidiano em detrimento de temas religiosos, do sublime...

2. Análise temática - A escolha de um tema - trabalho, medicina, lazer... - orienta essa opção, que vai buscar nas imagens produzidas ao longo da história da arte, a forma como foram representadas as diferentes maneiras de ser e viver de um determinado grupo social, em uma determinada época e apresenta-se como ideal para o trabalho com a história do cotidiano. Como se plantava, por exemplo, no Egito? E na Europa medieval? Qual era a situação dos negros no Brasil e na América do Norte nos regimes escravocratas? Nessa modalidade, é necessário trabalhar com as obras de vários artistas, pertencentes a espaços e temporalidades diferentes, promovendo a discussão em torno do tema, apontando as semelhanças e diferenças, contribuindo para o desenvolvimento nos alunos, do pensar historicamente - ou seja, da familiarização com a idéia de mudança.

\section{Análise a partir de questões e problemas} específicos - nesse caso, parte-se de uma problemática ou fato histórico localizado em um tempo e/ou espaço específicos para buscar como ele foi retratado por seus contemporâneos, por aqueles que o viveram. Desse modo, pode-se por exemplo, tentar entender como os processos de acelerada urbanização e crescimento das cidades, pautados em boa medida em avanços técnicos-científicos característicos do século XIX, foram interpretados pelos artistas em suas obras. Assim, tem-se a possibilidade de resgatar uma parte dos debates e diferentes 
posturas assumidas pelos habitantes dos grandes centros personificados neste caso também na figura do artista, as opiniões favoráveis e contrárias frente às tantas mudanças que estavam ocorrendo, procurando sempre relacionar as discussões com o tempo presente. Como vivemos nos centros urbanos hoje? O que é morar em Curitiba? Em São Paulo? Podemos, atualmente, falar em diferenças significativas entre campo e cidade?

4. O quadro de temática histórica - Esta última e mais conhecida opção diferencia-se de modo mais agudo das demais por trabalhar essencialmente com pinturas que retratam fatos $e$ eventos considerados históricos. Isso demanda um olhar diferenciado: qual é o saber histórico que está sendo transmitido? Qual a visão de história que está informando o autor do quadro? Como ele representa o seu tema? Nem verdade, nem necessariamente prova do real, o quadro deve ser entendido como fruto de uma determinada intencionalidade, historicamente situada, uma certa maneira de retratar o passado que se inscreve, como não poderia deixar de ser, no seu tempo presente. Desse modo, não é só pela historicidade da linguagem ou do tema que se pode propor atividades, mas também pela discussão do próprio saber histórico construído em torno da interpretação do fato retratado, no momento de sua produção e ao longo da historiografia produzida a respeito. É, portanto, no resgate do contexto e da história do tema retratado que se construiu através do tempo, no conteúdo e na linguagem, que encontramos mais uma possibilidade de abordagem pedagógica, como nos lembra o historiador Elias SALIBA (1998, p. 118) ao falar sobre a imagem fílmica.

No mesmo texto, o autor nos chama a atenção para a necessidade de se tratar as imagens não como evidência, mas como acontecimentos construídos por mediações. É preciso um saber que a mediatize pois ela não fala por si, "não ilustra e nem reproduz a realidade, ela a constrói a partir de uma linguagem própria que é produzida num dado contexto histórico" (IDEM, p. 119). Cabe ao professor o papel de mediar esse processo, resgatando na imagem, o acontecimento, a narrativa que the 
confere inteligibilidade e sentido, o caráter de imagem alegórica em oposição a uma imagem analógica "que apenas mostra" e é característica da produção imagética atual.

\section{Considerações finais}

De um modo geral, é extremamente necessário em qualquer abordagem histórico-pedagógica da obra de arte, tomar alguns cuidados. Primeiro, procurar entendê-la como, no mínimo, portadora de duas temporalidades: aquela do seu momento de produção e também a do seu momento de apropriação - não só a do tempo presente, mas o da sua recepção desde o momento da criação. Antes de perguntar somente pelo o que ela é como objeto artístico e o que representou, deve-se buscar o que ela pode nos dizer hoje, quais os seus sentidos na sociedade contemporânea. Ou então, o que representa a pintura para nossa cultura, como pensamos a arte dos nossos dias...

Em sala de aula, é preciso negociar os significados, ou seja, trabalhar com as leituras de obras, produzidas pelos próprios alunos. No primeiro contato com o quadro é possível elencar, além dos muitos elementos constituintes da obra, a sensação causada por ela, as primeiras impressões e leituras que, se bem encaminhadas pelo docente, podem dar margem à questionamentos extremamente profícuos. Sugere-se aqui, alguns procedimentos: a princípio uma leitura livre que, sem maiores informações a respeito da obra, leve a identificação do tema, espaço e tempo representado; das relações sociais, ações e personagens retratados; detalhes como vestimenta e objetos que podem caracterizar uma época ou um local, privilegiando as opiniões discentes. Em seguida, cabe analisar tecnicamente a obra $^{4}$, os elementos pictóricos que a compõem - linhas, cores, desenho, luz/sombra.. -, resgatando a vida do autor, seu estilo, obras, relacionando-os com a literatura crítica escrita a respeito,

\footnotetext{
${ }^{4}$ É claro que tais análises e leituras vão depender muito da disponibilidade de alunos e professores, das suas limitações acerca do saber artístico, da turma em que está sendo feito o trabalho, da idade e possibilidades de aprendizado dos alunos...e todas as demais questões para as quais nos chamam a atenção os tantos estudos sobre ensino e aprendizagem.
} 
colocando sempre que houver, opiniões dos próprios artistas. Vale ainda discutir a finalidade da obra; a relação com as técnicas e contextos de sua produção, circulação, apropriação e também seu caráter de verdade: até que ponto ela pode ser considerada fiel ao que pretende representar (WOODFORD, 1983, p. 12-13)? Todas essas informações devem ser articuladas com as interpretações feitas pelos alunos, não com o intuito de corrigilos, mas sim promover o debate através de comparações, evitando possíveis anacronismos e conduzindo a discussão em direção aos objetivos propostos pelo professor.

A realização de atividades posteriores ao trabalho com as imagens em sala, tais como a elaboração de um texto escrito sobre o que foi visto, as opiniões dos alunos sobre o quadro analisado ou mesmo uma releitura da obra feita através de atividades artísticas, - teatro, pintura, dança... - apresentam-se como práticas válidas na compreensão dos conteúdos históricos abordados, estimulando o aluno a construir suas próprias hipóteses explicativas e conclusões.

Segundo Fayga OSTROWER (1989, p. 167), "o ser humano é por natureza um ser criativo. No ato de perceber, ele tenta interpretar e, nesse interpretar, já começa a criar. Não existe um momento de compreensão que não seja ao mesmo tempo criação" ${ }^{5}$. Ou seja, a construção do conhecimento, em qualquer área, pressupõe interpretação, criação, subjetividade. Nesse sentido, a intenção do trabalho com as artes plásticas enquanto recurso didático é colocar o aluno em contato com diferentes representações de realidade, de espaços físico e temporais, de intenções e sentimentos, ampliando sua visão a respeito da história para que, estimulado pelo exercício da criatividade, seja seduzido pelo prazer do pensamento, do descobrir, podendo construir, também pela ação da escola, sua autonomia enquanto ser humano capaz de conhecer e interpretar o mundo.

${ }^{5}$ OSTROWER, Fayga. A construção do olhar. 
Abstract: The present article discusses some possible ways of utilizing plastic arts, more specifically paintings, as a means of teaching history. By enphasizing metodological questions, the authors seek to present, focusing on the dialogue between history and the theories of art, some alternatives to the well known work of utilizing paintings with a historical theme.

Key-words: 1 . History 2. Teaching 3. Arts 4. Paintings

\section{Referências bibliográficas}

COLI, Jorge. O que é arte? São Paulo: Círculo do Livro, 1983.

ELIAS, Norbert. Mozart - sociologia de um gênio. Rio de Janeiro: Jorge Zahar Editor, 1995.

OSTROWER, Faya. A construção do olhar. In: NOVAES, Adauto (org.). O olhar.

São Paulo: Cia das Letras, 1989.

SALIBA, Elias T. Experiências e representações sociais: reflexões sobre o uso e o

consumo das imagens. In: BITTENCOURT, Circe (org.).

O saber histórico

em sala de aula. São Paulo: Ed. Contexto,1998.

WOODFORD, Susan. A arte de ver a arte. São Paulo:

Círculo do livro, 1983. 